\title{
ANALISA SISTEM KERJA PERANGKAT AKTIF PT. TELKOM AKSES
}

\author{
Andika Singgih Prasetyo ${ }^{1)}$, Erlinasari ${ }^{2)}$ \\ ${ }^{1,2)}$ Program Studi Teknik Elektro, Fakultas Teknik, Universitas Semarang \\ Jalan Soekarno Hatta - Tlogosari, Semarang \\ e-mail: andikasinggihprasetyo@gmail.com ${ }^{1)}$, erlinasari@gmail.com $^{2)}$
}

\begin{abstract}
ABSTRAK
Penelitian ini bertujuan untuk mengetahui bagaimana sistem kerja di PT. Telkom Akses karena setelah penulis menganalisa sistem perangkat aktif PT. Telkom Akses, terdapat banyak manfaat bagi pelanggan ketika mereka mengalami kerusakan atau gangguan pada jaringan internet.

Objek penelitian dalam penelitian ini yaitu system perangkat aktif PT. Telkom Akses. Pengumpulan data dilakukan dengan Studi lapangan yang meliputi wawancara dan pengamatan secara langsung serta Studi kepustakaan berdasarkan pada literatur terkait objek penelitian.

Penulis hanya membahas dan menganalisa perangkat MSAN (Multi Service Access Node) saja. Hasil dari analisa tersebut adalah MSAN merupakan perangkat aktif karena mengaktifkan jaringan internet dan telepon sebelum ke pelanggan. Perangkat ini bergantung pada suplai listrik dari pln dan mendapat jaringan dari metro Ethernet menggunakan kabel FO (fiber optic).
\end{abstract}

Kata Kunci : Perangkat Aktif, Fiber Optic, Perangkat Aktif

\section{Pendahuluan}

$\mathrm{P}$ erkembangan teknologi saat ini berjalan seiring perekonomian yang berkembang semakin pesat. Setiap warga negara berusaha untuk mengembangkan teknologinya untuk dapat mendukung perekonomian negaranya. Salah satu faktor pendukung agar suatu negara tidak ketinggalan dengan negara lain adalah dengan adanya teknologi terkini yang diharapkan mampu menciptakan sumber daya manusia yang berkualitas dan berperan aktif sebagai aspek pembangunan yang dapat diandalkan.

Teknologi terkini diantaranya dipakai di PT.TelkomAkses yaitu sistem perangkat aktif yang sangat banyak manfaatnya bagi pelanggan, jika ada kerusakan atau gangguan pada jaringan internet pelanggan.

\section{METODE PENELITIAN}

Metode penelitian yang tepat akan menghasilkan data-data yang tepat dan terpercaya. Data-data yang tepat dan terpercaya sangat diperlukan untuk penyusunan suatu laporan yang baik dan benar. Guna mencapai hal tersebut, penulis menggunakan metode penelitian sebagai berikut :

\section{a. Objek Penelitian}

Objek penelitian adalah system kerja perangkat aktif di PT. Telkom Akses.

\section{b. Sumber Data}

Data-data yang penulis gunakan sebagai bahan penyusunan laporan ini berdasarkan sumbernya, secara garis besar dapat dibagi menjadi 2 kelompok :

1. Data Primer, adalah semua data yang bersumber langsung dari objek penelitian di lapangan.

2. Data Sekunder, adalah semua data yang bersumber selain dari objek penelitian di lapangan. Data ini penulis peroleh misalnya dari instruksi kerja, dokumen spesifikasi, buku literatur terkait dan sumber-sumber lainnya.

\section{c. Metode Pengumpulan Data}

Sedangkan metode pengumpulan data yang penulis terapkan antara lain :

1. Studi Lapangan, merupakan studi secara langsung terhadap objek penelitian melalui 2 cara :

- Metode Wawancara, dengan cara melakukan tanya-jawab secara langsung terhadap pembimbing lapangan yang kompeten yang ditunjuk oleh pihak PT. Telkom Akses.

- Metode Pengamatan, dengan cara melakukan pengamatan secara langsung terhadap objek penelitian serta membandingkan kebenarannya dengan data-data yang diperoleh melalui metode wawancara dan studi pustaka.

2. Studi Kepustakaan, merupakan studi secara tidak langsung terhadap objek penelitian melalui penelahan dan pengkajian data-data pendukung dari buku-buku literatur maupun dari sumber-sumber lainnya seperti dokumen pedoman dari sisitem perangkat aktif dalam telekomunikasi, artikel-artikel dari sumber terpercaya serta tidak menutup kemungkinan dari halaman situs yang dapat dipercaya kebenarannya. 


\section{ANALISIS DAN HASIL}

\section{a. Definisi Perangkat Aktif}

Perangkat aktif adalah merupakan suatu perangkat telekomunikasi yang sisitem kerjanya menerima data dari pusat transmisi kemudian menggabungkan dan memisahkan sinyal data dengan saluran telepon yang dipakai untuk mentransmisikan data serta mengolah data sebelum data itu sampai pada pelanggan.

Perangkat aktif dalam sistem telekomunikasi di PT. Telkom Akses Witel Semarang sebenarnya ada 2 perangkat yaitu DSLAM (Digital Subcriber Line Access Multiplexer) dan MSAN (Multi Service Access Node) seperti pada penjelasan sebelumnya, akan tetapi disini penulis akan membahas serta menganalisa perangkat MSAN saja.

Perangkat aktif MSAN (Multi Service Access Node) memiliki peran penting dalam sistem telekomunikasi di PT. Telkom Akses Witel Semarang, MSAN digunakan untuk mengoptimalkan media akses tembaga sebagai optimalisasi jaringan akses tembaga dari Metro atau pusat transmisi sampai ke pelanggan.

Penjelasan singkat tentang perangkat MSAN yaitu merupakan perangkat multi service bisa disebut juga perangkat yang bisa mengolah dan memilah data lebih dari satu data, cara kerja MSAN yaitu menerima sinyal data dari pusat transmisi atau metro-e kemudian data itu dipilah (suara dan data internet), sebelum diteruskan kepelanggan. MSAN merupakan sebuah perangkat pengolah serta pemilah data dari sumber transmisi sebelum data itu diteruskan sampai ke pelanggan.

MSAN merupakan perangkat yang sumber dayanya dari PLN ( perusahaan listrik negara), artinya MSAN dapat beroprasi atau bekerja jika mendapat sumber daya dari PLN.

Perangkat MSAN (Multi Service Access Node) terdiri dari beberapa modul, setiap modul memiliki fungsi yang berbeda-beda, dari modul power (PWX) untuk menghidupkan perangkat, modul suara (PVMD) sebagai penerima data suara (voice), modul internet (IPMD) sebagai penerima data internet dan juga modul pelanggan (CSRB) yang berfungsi sebagai penerus data untuk para pelanggan, seperti pembahasan sebelumnya.

\section{b. Sistem Kerja Perangkat Aktif MSAN (Multi} Service Access Node)

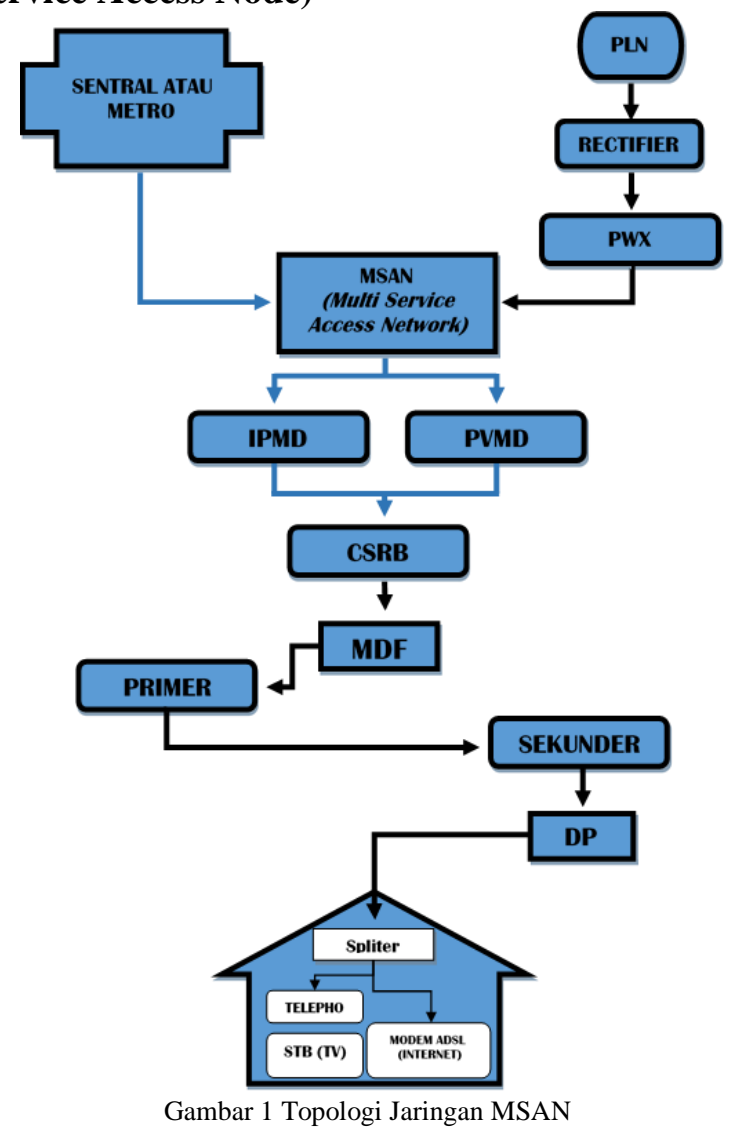

Perangkat aktif MSAN (Multi Service Access Network) dapat bekerja apabila terdapat sumber daya dari PLN (Perusahaan Listrik Negara) untuk topologi bisa dilihat pada gambar. Pertama sumber daya PLN masuk pada Rectifier, rectifier ini berfungsi sebegai pengubah arus bolak - balik (AC) menjadi DC, karena perangkat MSAN menggunakan arus searah (DC).

Kemudian setelah mendapat sumber daya dari PLN, perangkat MSAN dapat hidup dan berfungsi, MSAN mendapat masukan sumber data dari pusat transmisi atau Metro Ethernet (Me/Metro-E) . Metro ini adalah media transmisi data utama dalam jaringan telekomunikasi, semua data pusatnya adalah pada perangkat Metro ini, dari data internet, komunikasi (voice) dan juga useeTv.

Setelah mendapat sumber data dari Metro, data kemudian masuk ke perangkat MSAN melalui kabel tanah (feeder) dan masuk pada OTB (optical terminal network) yang kemudian masuk ke modul MSAN melalui kabel patchcore, modul yang ada pada perangkat MSAN untuk perangkat modul bisa dilihat pada gambar, didalam MSAN terdapat beberapa modul yang memiliki fungsi berbedabeda yaitu:

1. Modul PWX (power working), modul ini berfungsi sebagai power pada perangkat, jadi sumber daya dari PLN masuk ke modul PWX 
kemudian modul ini menghidupkan perangkat MSAN.

2. Modul IPMD (internet protocol management distribusi), modul ini bersungsi sebagai pemilah atau penyimpan data yang diterima dari Metro, data ini berupa data internet.

3. Modul PVMD (protocol voice management distribusi), modul ini berfungsi sebagai pemilah atau penyimpan data yang diterima dari Metro, data ini berupa suara.

4. Modul CSRB (control service request board), modul ini adalah modul utama sebelum data data dikirimkan ke pelangkat, atau biasa disebut dengan modul pelanggan. Setelah sumber data diolah pada modulmodul tersebut, data kemudian akan masuk pada MDF (Main Distribution Frame), data masuk ke $M D F$ dan diteruskan ke terminal primer kemudian ke terminal sekunder yang berfungsi sebagai tempat terminasi kabel yang menghubungkan kabel saluran pelanggan dari sentral telepon dan jaringan kabel yang menuju ke terminal pelanggan.

Setelah data masuk ke perangkat MSAN dan melewati beberapa perangkat yang ada dalam MSAN, kemudian data diteruskan ke DP (distribusi point) yang berfungsi sebagai tempat catuan atau terminal kabel dropwire (kabel penyambung dari distribusi ke splitter) dari kabel distribusi atau kabel udara diubah menjadi kabel dropwire yang kemudian diteruskan ke perangkat splitter pelanggan, didalam splitter terdapat 2 line atau jalur yaitu:

1. Line Pesawat Telepon, yang digunakan pelanggan untuk komunikasi (voice), bisa dilihat pada gambar 3.11, terdapat splitter yang mempunyai line bergambar telephone

2. Line Modul ADSL (Asychronus Digital Subscriber Line), yang digunakan untuk akses internet, didalam Modul ADSL bisa lihat pada gambar, serta dapat digunakan untuk useeTV dengan menambahkan perangkat STB (set top box).

Sumber data yang diterima oleh MSAN dari sentral atau Metro Enternet melalui kabel tanah (feeder) yang berjenis FO (fiber optik), kemudian masuk ke OTB (optical termination box) digunakan sebagai media penyambung dari kabel fiber optik ke switch dengan mengunakan kabel fiber optik patchcord setalah melalui OTB sumber daya masuk pada modul MSAN (sudah dijelaskan pada keterangan sebelumnya) setelah data keluar dari MSAN sudah tidak melalui fiber optik lagi, melainkan sudah menjadi kawat tembaga atau kabel yang kemudian masuk pada MDF (terminal primer kemudian sekunder) dan diteruskan ke DP (distribusi point) melalui kabel udara atau kabel distribusi, dari DP kemudian data diteruskan ke pelanggan melalui dropwire .

\section{c. Masalah Yang Sering Dialami Perangkat MSAN}

1. MSAN (Multi Service Access Network) merupakan perangkat yang hanya bisa bekerja jika mendapat sumber daya dari PLN, jadi jika listrik padam, maka perangkat MSAN tidak dapat beroprasi yang mengakibatkan pelanggan mengalami gangguan dalam sistem jaringan internet dan juga telepon.

2. Sumber data yang berupa (layanan internet) dan juga telepon dari pusat transmisi atau metro terkadang hilang, bisa dikarenakan usia fiber optik bisa juga dikarenakan kotornya fiber optik, jika fiber optik kotor bisa dibersihkan di ujung kabel fiber kemudian dipasang kembali akan tetapi jika pengaruh usia maka harus mencari jalur atau port baru agar data dapat kembali berjalan.

3. Modul perangkat MSAN down atau mengalami gangguan biasanya perangkat down bisa dikarenakan terlalu banyaknya keluaran data untuk para pelanggan, atau bisa juga karena sumber daya listrik yang baru masuk mengakibatkan MCB off atau mati (setelah terjadi pemadaman dari PLN).

\section{d. Kelebihan dari MSAN}

Keuntungan MSAN dapat memberikan nilai tambah, yaitu:

\section{Kemampuan MSAN}

MSAN menyediakan layanan narrowband untuk data dan suara (menggunakan POTS, ISDN PRA/BRA, digital leased line) dan layanan broadband untuk kemampuan internet, data dan multimedia yang meningkatkan kemampuan download file dan penjelajahan internet yang lebih cepat bagi endusers. Dengan fleksibilitas kemampuan multiservice ini akan mampu menyediakan operator telekomunikasi suatu kapasitas penghasilan yang lebih besar.

2. Kecepatan Operasional

Kabinet outdoor yang dikirimkan dalam bentuk complete-built atau data komplit yang telah mangalami proses pengujian di pabrik. Hal ini berarti node telah langsung siap untuk dioperasikan begitu dihubungkan dengan catuan listrik serta tersambung kejaringan transport dan koneksi ke end-user 
telah dibuat. Dari terminal local, provisioning system dapat dilakukan sehingga

\section{f. Analisa Mengenai Perangkat MSAN}

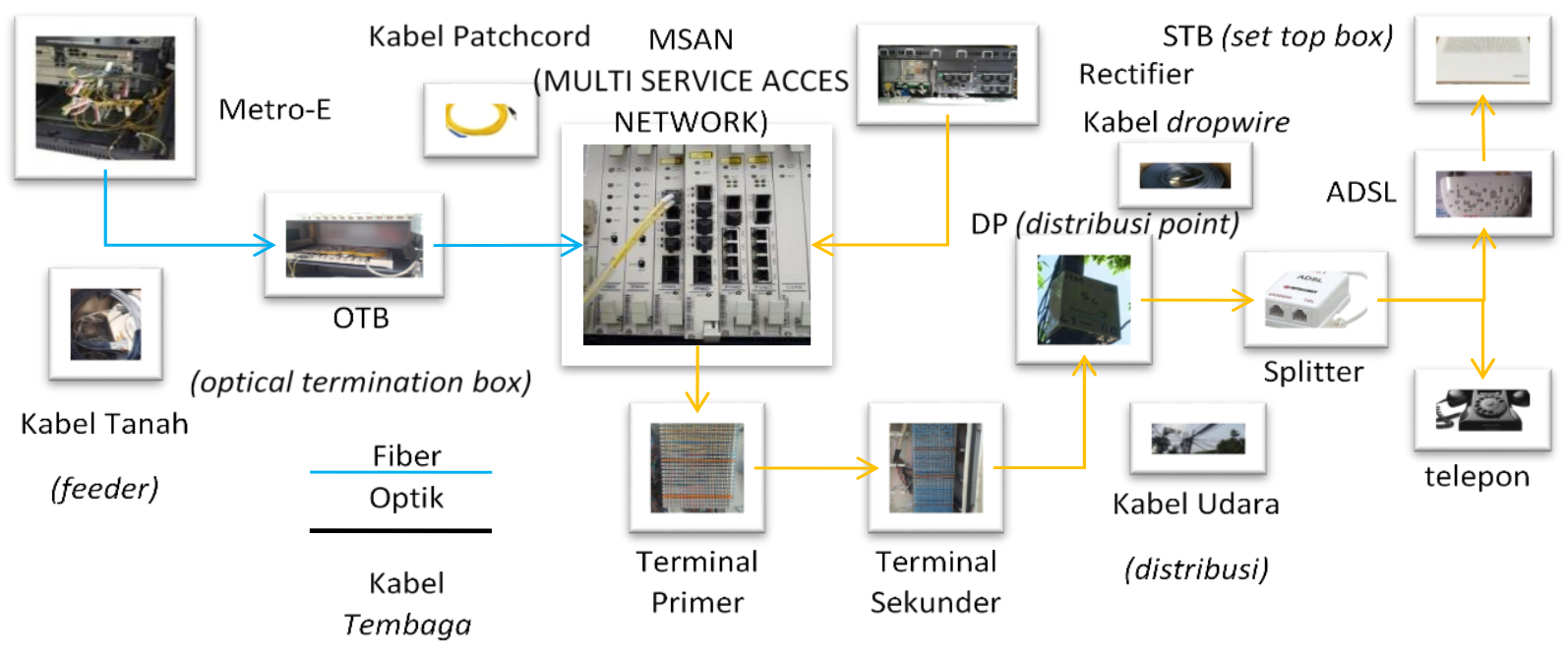

memungkinkan MSAN untuk dapat langsung operasional dalam waktu yang cukup pendek secara signifikan berarti mengefektifkan waktu yang diperlukan untuk mengatur pendapatan.

3. Cakupan Topologi Yang Luas

Cakupan topologi yang luas serta kapasitas dan penempatan MSAN memastikan bahwa pilihan terbaik dari sisi ekonomis maupun teknis selalu ada sehingga akan meminimalisasi biaya investasi untuk mendapatkan keuntungan atau pengembalian modal yang maksimum.

\section{e. Kekurangan dari MSAN}

1. Jika modul perangkat down atau gangguan, maka banyak pelanggan yang tidak bisa menggunakan akses layanan telekomunikasi yaitu berupa layanan suara (voice) dan juga internet.

2. Karena perangkat MSAN (Multi Service Access Network) hanya dapat bekerja jika ada sumber daya dari PLN, jadi jika PLN ada pemadaman perangkat aktif MSAN tidak dapat bekerja atau beroprasi, maka para pelanggan juga tidak dapat menggunakan layanan yang disediakan dari PT. Telkom Akses.

3. Biasanya banyak terjadi data yang tidak terdeteksi didalam modul - modul MSAN, jadi untuk menormalkan atau mengembalikan data perangkat maka modul harus direstart, dengan cara melepas modul lalu memasangnya kembali. Efek dari data yang tidak terdeteksi mengakibatkan perangkat MSAN tidak dapat menghantarkan informasi ke para pelanggan.
Gambar 2 Rangkaian jaringan MSAN

MSAN (Multi Service Access Network) merupakan suatu perangkat aktif yang berfungsi sebagai penerima data dari pusat atau Metro mendistribusikan data sebelum diteruskannya data - data itu ke pelanggan, Metro-E ini bertempat di STO (Sentral Office). STO ini adalah tempat perangkat transmisi utama jaringan milik Telkom.

Data yang diterima dari pusat data atau Metro yaitu berupa suara (voice), kemudian data internet serta Vidio (UseeTV). Data tersebut masuk ke perangkat MSAN dengan menmggunakan kabel feeder atau kabel tanah kemudian masuk pada OTB (optical terminaton box) menggunakan kabel patshcore yang berjenis fiber optik kemudian menuju modul yang mempunyai fungsi berbeda-beda, data suara (voice) masuk kedalam modul PVMD (protocol voice management distribusi), kemudian data internet dan juga vidio masuk pada modul IPMD (internet protocol management distribusi), yang kemudian diteruskan ke modul CSRB (control service request board) yang berfungsi sebagai penerus semua data tersebut ke pelanggan, dari CSRB kemudian menuju terminal primer dan sekunder sampai ke pelanggan menggunakan kabel tembaga, untuk kejelasan alur kerjanya bisa dilihat pada penjelasan sebelumnya.

MSAN hanya dapat bekerja jika mendapat sumber daya dari PLN, jika PLN padam, perangkat MSAN akan ikut padam dan mengakibatkan terjadinya gangguan pada pelanggang, gangguan itu berupa pelanggan tidak bisa mengakses internet juga telepon, maka sebaiknya ditambahkan perangkat pendukung 
lainnya seperti battery supaya MSAN dapat bekerja sementara disaat listrik padam.

MSAN bisa disebut juga dengan perangkat penerus kerja dari Metro-E dalam perangkat Metro-E atau satu modul perangkat Metro-E biasanya mencakup 10 sampai 15 MSAN dan satu MSAN mencakup 250 sampai 300 pelanggan.

\section{KESIMPULAN}

Berdasarkan pembahasan yang telah penulis uraian tentang analisa sistem kerja perangkat aktif pada telekomunikasi, dapat disimpulkan sebagai berikut :

1. MSAN (Multi Service Access Network) disebut dengan perangkat aktif karena perangkat tersebut yang mengaktifkan jaringan internet dan juga telepon sebelum diteruskannya ke pelanggan.

2. Dalam perangkat Metro-E atau satu modul perangkat Metro-E biasanya mencakup 10 sampai 15 MSAN dan satu MSAN mencakup 250 sampai 300 pelanggan. Perangkat MSAN dapat bekerja karena adanya sumber daya dari PLN, jadi jika PLN padam maka MSAN tidak dapat bekerja dan ada 250 sampai 300 pelanggan yang tidak bisa menggunakan layanan.

MSAN mendapat sumber data dari Metro Enthernet (sentral) menggunakan FO (fiber optic) dan keluaran menuju ke pelanggan menggunakan kawat tembaga. Berikut beberapa saran yang diharapkan dapat bermanfaat adalah sebagai berikut:

1. Perangkat aktif terkadang mengalami gangguan, seperti modul eror, konektifitas terputus. Jadi harus lebih berhati-hati dalam mengecek gangguan tersebut.

2. Melakukan perawatan secara berkala sebagai upaya mengurangi kemungkinan terjadi gangguan pada perangkat.

3. Penambahan battery pada perangkat sebagai pengganti sumber daya jika terjadi pemadaman PLN maka perangkat masih dapat bekerja.

\section{DAFTAR PUSTAKA}

[1] Modul -1 Overview Fiber to the "x" (FTTX) PT. Telkom Akses Witel Semarang.

[2] Materi basic FTTH network 20160308 PT. Telkom Akses Witel Semarang.

[3] https://onegrouptkj.wordpress.com/2015/09/02/m-s-a-n/

[4] https://r341153.wordpress.com/ilmu/it-network/dslam/ 